\title{
Health-related quality of life and disease progression in pulmonary arterial hypertension patients: a 3-year study
}

\author{
Laurence Halimi ${ }^{1}$, Carey M. Suehs $\mathbb{1}^{1,2}$, Gregory Marin ${ }^{2}$, Clement Boissin ${ }^{1}$, Anne-Sophie Gamez ${ }^{1}$, \\ Isabelle Vachier ${ }^{1}$, Nicolas Molinari ${ }^{2,3}$ and Arnaud Bourdin (10)
}

${ }^{1}$ Dept of Respiratory Diseases, Université de Montpellier, CHU Montpellier, Montpellier, France. ${ }^{2}$ Dept of Medical Information, Université de Montpellier, CHU Montpellier, Montpellier, France. ${ }^{3}$ IMAG, CNRS, Université de Montpellier, CHU Montpellier, Montpellier, France. ${ }^{4}$ PhyMedExp, Université de Montpellier, CNRS, INSERM 1046, CHU Montpellier, Montpellier, France.

Corresponding author: Laurence Halimi (l-halimi@chu-montpellier.fr)

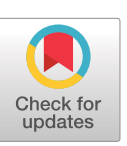

Copyright @The authors 2021

This version is distributed under the terms of the Creative Commons Attribution Non-Commercial Licence 4.0. For commercial reproduction rights and permissions contact permissions@ersnet.org

Received: 27 Aug 2020 Accepted: 27 March 2021

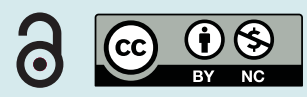

Shareable abstract (@ERSpublications)

Baseline subscale SF-36 Physical Functioning questionnaire for PAH patients is independently associated with disease progression at 3 years. HRQoL should be considered as a complement to risk assessment criteria. https://bit.ly/3mrZhHT

Cite this article as: Halimi L, Suehs CM, Marin G, et al. Health-related quality of life and disease progression in pulmonary arterial hypertension patients: a 3-year study. ERJ Open Res 2021; 7: 006172020 [DOI: 10.1183/23120541.00617-2020].

\section{Abstract}

Objectives The role of health-related quality of life (HRQoL) and psychological variables in pulmonary arterial hypertension (PAH) progression remains poorly quantified. We aimed to investigate the relationship between disease progression in PAH patients and HRQoL and psychological characteristics.

Methods A 3-year longitudinal cohort was initiated. Patients with stable PAH (groups I-IV ineligible for angioplasty/endarterectomy) were included $(n=55)$. Standard clinical variables, including invasive haemodynamic parameters, were prospectively recorded. A battery of questionnaires was used to characterise the psychological status of patients upon study initiation, and HRQoL was quantified using the SF-36 Questionnaire every 3 months for 24 months, and then again at 36 months. Guideline-defined disease progression and progression-free survival were recorded for 36 months.

Measurements and main results Psychological distress was highly prevalent at baseline. The Physical Component Summary (PCS) and the Mental Component Summary (MCS) of the HRQoL were poor (PCS=37.13 \pm 8.18 ; MCS=42.42 \pm 10.88 ) but stable over 3 years of follow-up. Among PCS subscales, Physical Functioning (PF) $(\mathrm{p}=0.012)$ was identified as being independently associated with disease progression (Cox survival model), along with mean pulmonary arterial pressure $(p=0.003)$ and cardiac output $(\mathrm{p}=0.005)$. Depression was the unique independent psychological characteristic associated with PF $(\mathrm{p}=0.0001)$.

Conclusions PAH patients have poor HRQoL. In addition to already known criteria related to disease severity, the HRQoL PF subscale is independently associated with disease progression in PAH. This may be explained by depression.

\section{Introduction}

Pulmonary arterial hypertension (PAH) is a rare and progressive disease caused by persistent elevation of pulmonary arterial pressure leading to right-side heart failure [1]. At onset of PAH, symptoms remain nonspecific (fatigue, shortness of breath on exertion and exercise limitations) and a delay in diagnosis is frequent, draining patients of their psychological resources. According to the national data registry, there were approximately $1700 \mathrm{PAH}$ patients in France in 2006, and between 15 and 50 cases per million individuals worldwide [2]. Over the past three decades, medical treatments have been developed and overall prognosis has improved [3] but mortality remains high and increasing survival remains a research priority. Improving health-related quality of life (HRQoL) has also become an essential objective supported by patients [4, 5].

Most clinical assessments during follow-up are integrated within a prognostic evaluation system based on right atrial pressure, cardiac output, 6-min walking distance (6MWD), pericardial effusion and right atrial 
surface, N-terminal pro-B-type natriuretic peptide, maximal oxygen uptake, symptoms (New York Heart Association (NYHA), syncope) and their progression. Although poor HRQoL is reported in this disabling disease, whether or not HRQoL should be considered as a prognostic criterion has not been addressed. In incident patients, HRQoL is a prognostic marker [5] that can change with time, together with the health context [6]. However, systematic longitudinal evaluation by clinicians is not practised [7] and even in research situations, repeated evaluations remain rare. To our knowledge, no PAH study has regularly monitored HRQoL over a relatively long timespan.

The most common generic HRQoL evaluation is the Medical Outcomes Study 36-item Short-Form Health Survey (SF-36) Questionnaire [8], for which minimally important differences have been determined in $\mathrm{PAH}$ [9]. Several studies have found improved or unchanged SF-36 scores following various treatment trials in PAH $[5,10]$. A systematic review underlined the heterogeneity of results, as well as the limited availability of data concerning their prognostic significance [11]. It is therefore still unclear whether poor HRQoL in PAH should be seen as a cofactor and eventually as an expected consequence of the disease or if it should be seen as a prognostic criterion.

The self-assessment of HRQoL is a cognitive process, and therefore open to the influence of psychological factors [12]. PAH impacts involving anxiety and depression have been repeatedly demonstrated [13, 14]. Current guidelines therefore stress the association between anxiety and depression and poor HRQoL [4]. Other psychological factors have the potential to expand our understanding of HRQoL [15]. Within this context, we initiated a 3-year study to evaluate HRQoL in PAH patients with stable disease versus those who had acute disease aggravation. Associations with baseline clinical and psychological characteristics were also tested.

\section{Methods}

Study population

The HyPsy protocol (ClinicalTrials.gov NCT01380054; https:/osf.io/8qduc/) included 55 PAH patients from May 2011 to November 2012 at the Arnaud de Villeneuve Hospital (Montpellier University Hospitals, France). The study was approved by an independent ethics committee (Comité de Protection des Personnes - SudMéditerranée III; reference number: 2011.04.01) and all patients gave their informed consent to enter the study in accordance with French law. Briefly, this 3-year longitudinal study included patients aged 18 to 80 years who had stable PAH for at least 3 months and no prior psychological care/ support.

\section{Patient monitoring for 3 years}

Relevant right heart catheterisation variables were measured at baseline. Data concerning the baseline 6-min walk test (6MWT) were also recorded: distance walked (in metres and classified as above or below a $400 \mathrm{~m}$ threshold), the associated Borg scale (score from 0 to 10); heart rate at the beginning and end of the test $\left(\mathrm{HR}_{\mathrm{start}}\right.$ and $\mathrm{HR}_{\text {stop }}$; beats per minute (bpm)), peripheral capillary oxygen saturation $\left(S_{\mathrm{pO}_{2}}\right)$ at the beginning and end of the test $\left(S_{\mathrm{pO}_{2}}\right.$ start and $S_{\mathrm{pO}_{2}}$ stop; \%), and whether or not the latter two measures differed by at least $4 \%$, indicating a clinically significant change in $S_{\mathrm{pO}_{2}}$ during the $6 \mathrm{MWT}\left(\Delta \mathrm{S}_{\mathrm{pO}_{2}} 4 \%\right.$; yes/no).

Baseline psychological assessments included questionnaires describing anxiety and depression, coping mechanisms, perceived social support and beliefs concerning perceived control (table 1). HRQoL was also measured every 3 months for 24 months and then again at 36 months using the SF-36 Questionnaire [8]. Disease progression (defined as aggravation requiring a change in treatment or death) versus disease stability was also monitored for 36 months, and triggered an additional HRQoL evaluation.

\section{Statistics}

Quantitative variable distributions were evaluated using the Shapiro-Wilk test, and normal variables summarised via their means and standard deviations. Other quantitative variables were presented as medians accompanied by their interquartile ranges and qualitative variables as numbers and percentages. Baseline characteristics were compared between stable and disease-progression patients with t-tests or Mann-Whitney U-tests, as appropriate.

Cox models were used to analyse the relationships between baseline clinical and HRQoL variables and progression-free survival (delay to disease progression or death). Univariate models were first carried out, and variables with p-values $<0.15$ were entered into a multivariable Cox model with forward selection. The coefficients with $95 \%$ confidence intervals (CI) are provided for the final model including only those variables independently and significantly associated with progression-free survival. A bootstrapping of the 
TABLE 1 Presentation of psychological evaluation tools used

\begin{tabular}{|c|c|c|c|}
\hline Questionnaire, purpose and item example & Likert scale used & Subscales/dimensions & Interpretation rules (if any) \\
\hline $\begin{array}{l}\text { HADS: Hospital Anxiety Depression Scale } \\
\text { [30,31] } \\
\text { The HADS detects anxiety and/or depression, } \\
\text { evaluates their severity and avoids confusion } \\
\text { with somatic illnesses. } \\
\text { I have lost interest in my appearance. }\end{array}$ & $\begin{array}{l}4 \text { levels } \\
0 \text { to } 3\end{array}$ & $\begin{array}{l}\text { Depression (14 items) } \\
\text { Anxiety (14 items) }\end{array}$ & $\begin{array}{c}\text { Non-cases: } 0-7 \\
\text { Possible cases: } 8-10 \\
\text { Probable cases: } 11-21 \\
\text { Global score: } \\
\text { No anxio-depressive disorders: } 0-14 \\
\text { Anxio-depressive disorders: } 15-42\end{array}$ \\
\hline $\begin{array}{l}\text { CHIP: Coping with Health Injuries and } \\
\text { Problems [34, 35] } \\
\text { The CHIP, specific to health-related problems, } \\
\text { refers to the thoughts and actions we use to } \\
\text { deal, in order to master, minimise or tolerate } \\
\text { stress and threatening situations. } \\
\text { I wonder why it happened to me }\end{array}$ & $\begin{array}{l}5 \text { levels } \\
\text { "Not at all” to } \\
\text { "Very much" } \\
\text { (1 to } 5)\end{array}$ & $\begin{array}{c}\text { Distraction coping } \\
\text { (D;8 items) } \\
\text { Instrumental coping } \\
\text { (I; } 8 \text { items) } \\
\text { Emotional preoccupation } \\
\text { (E; } 8 \text { items) } \\
\text { Palliative coping (P; } 8 \text { items) }\end{array}$ & $\begin{array}{l}\text { Likert scores are summed per subscale. } \\
\text { Subscale sums are then transformed } \\
\text { according to age and sex. The latter } \\
\text { (T-scores) have a mean of } 50 \text { and a } \\
\text { standard deviation of } 10 .\end{array}$ \\
\hline $\begin{array}{l}\text { WCC: Ways of Coping Checklist }[36,37] \\
\text { The WCC identifies, from a stressful situation } \\
\text { not linked to the disease (divorce, moving, } \\
\text { conflict, etc.), strategies which have been } \\
\text { used to confront the situation. } \\
\text { I accepted sympathy and understanding from } \\
\text { someone }\end{array}$ & $\begin{array}{l}4 \text { levels } \\
\text { "No" to "Yes" } \\
\text { (0 to } 3 \text { ) }\end{array}$ & $\begin{array}{l}\text { Problem-focused (9 items) } \\
\text { Emotion-focused ( } 9 \text { items) } \\
\text { Search for social support ( } 9 \\
\text { items) }\end{array}$ & $\begin{array}{c}\text { Possible scores range from } 0 \text { to } 27 \text { for each } \\
\text { subscale }\end{array}$ \\
\hline $\begin{array}{l}\text { SSQ6: Short Form of the Social Support } \\
\text { Questionnaire [38, 39] } \\
\text { The SSQ intends to quantify the dimensions } \\
\text { of perceived availability of and satisfaction }\end{array}$ & $\begin{array}{l}6 \text { levels } \\
\text { "Very satisfied" } \\
\text { to "Very } \\
\text { dissatisfied" }\end{array}$ & $\begin{array}{l}\text { Number of available people } \\
\text { (N; } 6 \text { items with up to nine } \\
\text { people in each item) } \\
\text { Satisfaction (S; } 6 \text { items) }\end{array}$ & $\begin{array}{l}\text { SSQ Number score }(\mathrm{N}) \text { : the total score } \\
\text { ranges between } 0 \text { and } 54 \\
\text { SSQ Satisfaction score }(\mathrm{S}) \text { : the total score } \\
\text { ranges between } 6 \text { and } 36\end{array}$ \\
\hline
\end{tabular}

Whom can you really count on to help you feel

more relaxed when you are under pressure or

tense?

(For each item, there is a two-part answer:

Part 1: list all the people that fit the

description of the question. Part 2: use the

Likert scale to indicate satisfaction)

MHLC-C: Multidimensional Health Locus of

Control Form C $[39,40]$

This scale measures health-specific locus of control along four dimensions. The extent to which individuals believe that: 1 ) health is a consequence of their own actions, 2) under the influence of doctors, 3) under the influence of powerful others, 4) due to chance.

Form C is designed to be "condition-specific", i.e. used when studying people with an existing health condition.

Other people play a big role in whether my condition improves, stays the same or gets worse

$\begin{array}{cc}6 \text { levels } & \text { Internal (I; } 6 \text { items) } \\ \text { "Strongly } & \text { External: Chance (C; } 3 \text { items) } \\ \text { disagree" to } & \text { External: Doctors (D; } 3 \text { items) } \\ \text { "Strongly agree" } & \text { External: Powerful others } \\ \text { (1 to } 6) & (0 ; 6 \text { items) }\end{array}$

Possible range: Internal and Chance: 6-36

Doctors and Other powerful people: $3-18$

Cox model was carried out, via case resampling with replacement. 1000 bootstrapped samples were calculated, and the Cox models were executed in each sample.

Mixed models were used to study the impact of time, disease stability and potential time $\times$ disease stability interactions on subscales (Physical Functioning (PF), Physical Component Summary (PCS), Mental Component Summary (MCS)) of the SF-36 HRQoL Questionnaire. 
In order to better understand the psychological characteristics potentially associated with HRQoL, linear regression models were performed with $\mathrm{PF}$ as the dependent variable and baseline psychological variables as independent variables. As with Cox models, variables with a univariate result of $\mathrm{p}<0.15$ were retained for analysis at the multivariable level using a forward stepwise method.

Statistical analyses were performed using SAS 9.1 software (SAS Institute, Cary, NC, USA) and R v.3.1.1 (The R Foundation for Statistical Computing), and the statistical bilateral significance threshold was set at 5\%.

\section{Results}

Baseline description of the population and initial results

Demographic characteristics, anxiety and depression Hospital Anxiety Depression Scale (HADS), State and Trait anxiety (STAI-Y), coping (CHIP and WCC) and HRQoL (SF-36) baseline values for the total population have been previously reported in detail [16]. Briefly, the population had a mean age of $57.8 \pm 15.3$ years, and was $64 \%$ women. A slight majority (51\%) of patients suffered from anxiety and depression (HADS anxiety and depression scores: $8.7 \pm 4.7$ and $6.16 \pm 3.9$, respectively). Patients had moderate to very high state (60\%; STAI-Y state anxiety: $48.2 \pm 7.5)$ and trait (64\%; STAI-Y trait anxiety: $50.5 \pm 14.0$ ) anxiety, especially for men. Stressful-life-event-coping (WCC) and disease-coping (CHIP) strategies focused on problem coping strategies. HRQoL was poor and the mean values for the PCS (37.1 \pm 8.03$)$ and the MCS $(42.4 \pm 10.9)$ were particularly low. Regarding medical parameters, the patients included were fairly representative of the population usually described for PAH [4]. More than 50\% were in functional classes I-II and the mean $6 \mathrm{MWD} \pm \mathrm{SD}$ was $382 \pm 33 \mathrm{~m}$. The haemodynamic parameters for those patients who were already being treated (58\% receiving bi- or tri-therapy) corresponded to severe PAH (pulmonary vascular resistance of 10.0 \pm 6.6 Wood's units) but with conserved cardiac output. Multivariate analysis showed a significant positive relationship between 6MWD and PCS and a significant negative relationship between delta $\mathrm{S}_{\mathrm{pO}_{2}} \geqslant 4 \%$ and MCS. Depression and Trait-Anxiety were associated with a lower physical $(\mathrm{p}=0.001)$ and mental $(\mathrm{p}<0.001)$ HRQoL, respectively [16].

\section{Differences between progression-free and disease-progression groups}

Baseline values for stable and unstable (i.e. patients with no observed disease progression during the 3 years of follow-up versus those who were observed to decline) patient groups are presented in tables 2 and 3. Certain clinical variables significantly differed between the two groups, including mean pulmonary arterial pressure, PAH treatments, NYHA class and 6MWT results (distance and oxygen saturation at the beginning and end of the test). Both the PCS and MCS were higher ( $\mathrm{p}=0.06 ; \mathrm{p}=0.04)$ in the stable group. All anxiety-related scores (STAI-Y state and trait anxiety scores, the HAD anxiety, depression and total scores) were significantly worse $(\mathrm{p}=0.03 ; \mathrm{p}=0.01 ; \mathrm{p}=0.05 ; \mathrm{p}=0.01, \mathrm{p}=0.01$, respectively) in the unstable group. The WCC emotion score was significantly higher $(p=0.03)$ in the unstable group, which indicates that the coping strategies used to manage stressful life events are more focused on emotional responses (table 3).

\section{Explaining progression-free survival}

The progression-free survival curve is presented in figure 1; $54 \%$ of the study population (which included $0 \%$ lost to follow-up) was progression-free at the end of 3 years of follow-up. According to the survival curve, aggravation occurred linearly. At the univariate level, several clinical variables were found to be associated with progression-free survival: NYHA class, mean pulmonary arterial pressure, cardiac output, right atrium pressure and 6MWT results (distance, the $400 \mathrm{~m}$ threshold and oxygen saturation at the beginning and end of the test). Regarding HRQoL variables, all the SF-36 Questionnaire subscales, except Bodily Pain and General Health, were associated with progression-free survival.

At the multivariable level, mean pulmonary arterial pressure (hazard ratio (HR) 1.053; 95\% CI 1.023 1.084; $\mathrm{p}=0.0153$ ), cardiac output (HR 1.559; 95\% CI 1.189-2.045; $\mathrm{p}=0.0013$ ) and the PF subscale (HR 0.978; 95\% CI 0.962-0.995; $\mathrm{p}=0.0106$ ) were significantly associated with progression-free survival (table 4). The bootstrapping approach confirms these results.

\section{Stability of HRQOL over time}

When examining the PF subscale of the SF-36 Questionnaire as a function of time and disease stability via a mixed model, only disease stability versus instability was significantly associated with $\mathrm{PF}$ (coefficient=18.53; sE=7.22; $\mathrm{p}=0.013$ ). No association with time or the interaction term (stability $\times$ time) was found, indicating that the PF subscale was stable throughout the 3 years of complete follow-up (figure 2). PCS and MCS were also stable across time (figure 3). Given this stability, we further explored the contributions of psychological variables to PF scores at baseline. 


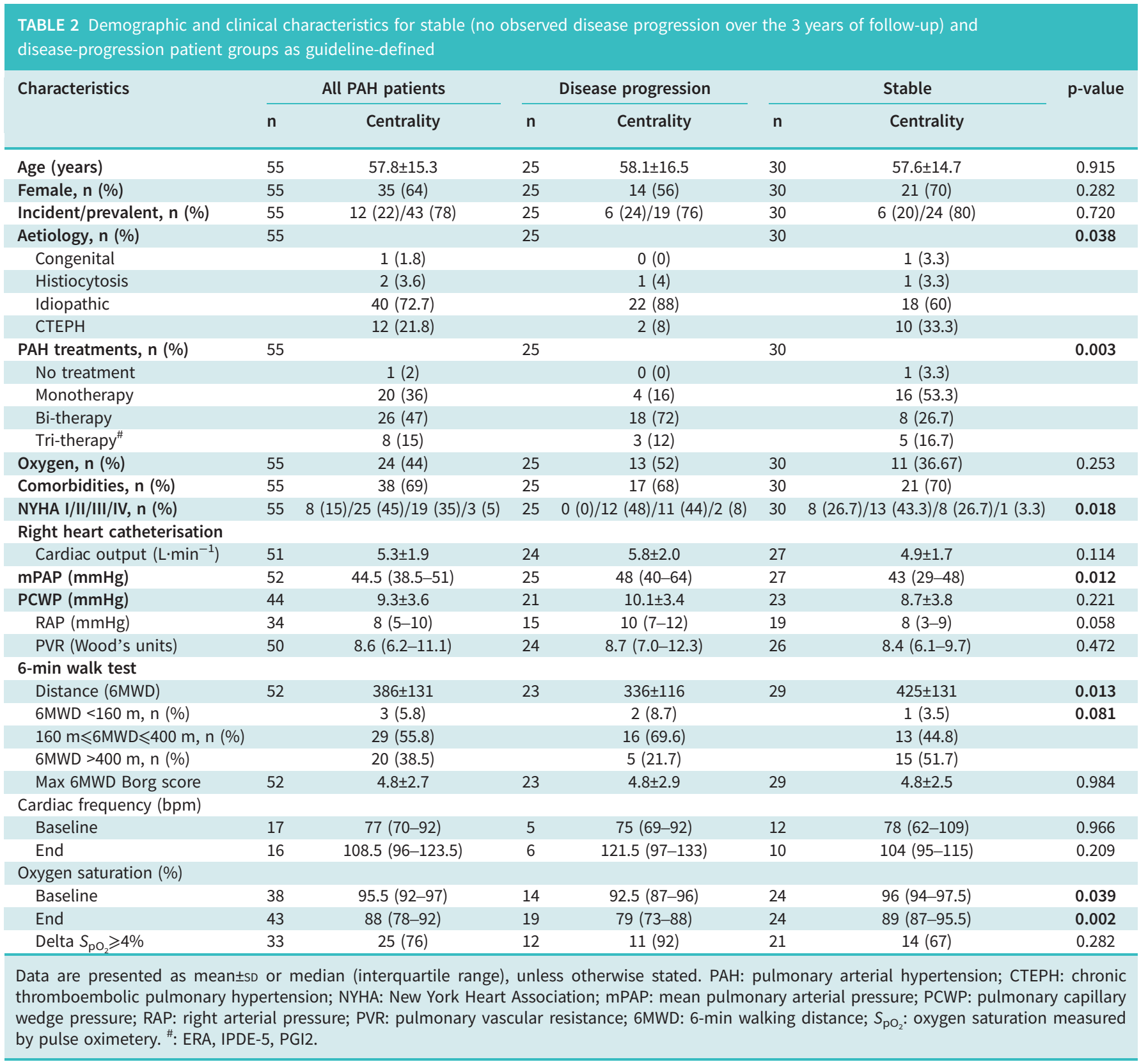

Association between PF subscale and baseline psychological variables

When examining the relationships between baseline psychological variables and the HRQoL PF subscale, several significant associations were demonstrated at the univariate level (table 5), including negative associations with anxiety and depression variables and the CHIP Emotion score. At the multivariable level, only the HADS Depression score (coefficient=-3.26; $\mathrm{sE}=0.79 ; \mathrm{p}=0.0001$ ) was significantly negatively associated with the PF subscale.

\section{Discussion}

This study demonstrates a positive, independent association between progression-free survival and the SF-36 HRQoL PF subscale score in a 55-patient PAH cohort with no loss to follow-up over a 3-year period. Unexpectedly, PF and both the MCS and PCS scores were stable over the entire study period. Progression-free survival was associated with clinical findings comprising negative relationships with mean pulmonary arterial pressure and cardiac output. A battery of baseline psychological tests further demonstrated differences between the stable and disease-progression patient groups that complement differences in HRQoL. Specifically, depression was negatively associated with the PF subscale. 
TABLE 3 Health-related quality of life and psychological baseline characteristics for stable (no observed disease progression over the 3 years of follow-up) and disease-progression patient groups

\begin{tabular}{|c|c|c|c|c|c|c|c|}
\hline \multirow[t]{2}{*}{ Characteristics } & \multicolumn{2}{|c|}{ Total population } & \multicolumn{2}{|c|}{ Disease progression } & \multicolumn{2}{|r|}{ Stable } & \multirow[t]{2}{*}{$\mathrm{p}$-value } \\
\hline & $\mathrm{n}$ & Centrality & $\mathrm{n}$ & Centrality & $\mathrm{n}$ & Centrality & \\
\hline \multicolumn{8}{|c|}{ SF-36: Health-Related Quality of Life } \\
\hline PCS & 55 & $37.13 \pm 8.18$ & 25 & $34.81 \pm 7.28$ & 30 & $39.04 \pm 8.50$ & 0.060 \\
\hline Physical functioning & 55 & $50.00(25.0-65.0)$ & 25 & $32.50(15.0-62.5)$ & 30 & $55.00(40.0-75.0)$ & 0.013 \\
\hline Role-physical & 55 & $25.00(0.0-75.0)$ & 25 & $12.50(0.0-50.0)$ & 30 & $50.00(0.0-75.0)$ & 0.039 \\
\hline Bodily pain & 55 & $52.00(41.0-84.0)$ & 25 & $41.00(36.0-72.5)$ & 30 & $52.00(42.0-84.0)$ & 0.098 \\
\hline General health & 55 & $35.00(30.0-47.0)$ & 25 & $35.00(23.5-45.0)$ & 30 & $35.00(30.0-50.0)$ & 0.219 \\
\hline MCS & 55 & $42.42 \pm 10.88$ & 25 & $38.98 \pm 11.77$ & 30 & $45.05 \pm 9.39$ & 0.042 \\
\hline Vitality & 55 & $45.64 \pm 17.82$ & 25 & $41.60 \pm 18.13$ & 30 & $49.00 \pm 17.14$ & 0.099 \\
\hline Social functioning & 55 & $62.50(50.0-75.0)$ & 25 & $62.50(25.0-68.7)$ & 30 & $62.50(50.0-75.0)$ & 0.043 \\
\hline Role-emotional & 55 & $33.33(0.0-100.0)$ & 25 & $16.67(0.0-83.3)$ & 30 & $66.67(33.3-100.0)$ & 0.047 \\
\hline Mental health & 55 & $56.00 \pm 18.60$ & 25 & $50.56 \pm 17.51$ & 30 & $60.53 \pm 18.55$ & 0.016 \\
\hline \multicolumn{8}{|c|}{ HADS: Hospital Anxiety Depression Scale } \\
\hline Anxiety & 55 & $9.0(4.0-12.0)$ & 25 & $10.0(8.0-12.0)$ & 30 & $5.0(4.0-11.0)$ & 0.054 \\
\hline Depression & 55 & $6.0(2.0-10.0)$ & 25 & $9.0(5.0-11.0)$ & 30 & $4.0(2.0-7.0)$ & 0.010 \\
\hline Total score & 55 & $17.0(8.0-22.0)$ & 25 & $18.0(13.0-23.0)$ & 30 & $9.5(3.0-25.0)$ & 0.015 \\
\hline \multicolumn{8}{|c|}{ STAI-Y: State-Trait Anxiety Inventory Form Y } \\
\hline State anxiety & 55 & $48.48 \pm 7.50$ & 25 & $50.52 \pm 7.54$ & 30 & $46.23 \pm 7.01$ & 0.033 \\
\hline Trait anxiety & 55 & $50.55 \pm 14.52$ & 25 & $55.52 \pm 13.68$ & 30 & $46.40 \pm 14.10$ & 0.018 \\
\hline \multicolumn{8}{|c|}{ CHIP: Coping with Health Injuries and Problems } \\
\hline Distraction & 55 & $27.35 \pm 6.57$ & 25 & $26.16 \pm 6.57$ & 30 & $28.33 \pm 6.51$ & 0.298 \\
\hline Palliative & 55 & $26.11 \pm 4.76$ & 25 & $25.56 \pm 4.95$ & 30 & $26.57 \pm 4.64$ & 0.737 \\
\hline Instrumental & 55 & $30.44 \pm 6.17$ & 25 & $29.96 \pm 6.19$ & 30 & $30.83 \pm 6.22$ & 0.246 \\
\hline Emotional preoccupation & 55 & $25.13 \pm 7.48$ & 25 & $26.28 \pm 7.27$ & 30 & $24.17 \pm 7.63$ & 0.206 \\
\hline \multicolumn{8}{|c|}{ WCC: Ways of Coping Checklist } \\
\hline WCC problem & 53 & $26.28 \pm 5.55$ & 24 & $26.29 \pm 5.15$ & 29 & $26.28 \pm 5.96$ & 0.991 \\
\hline WCC emotion & 53 & $23.23 \pm 5.79$ & 24 & $25.04 \pm 5.82$ & 29 & $21.72 \pm 5.40$ & 0.036 \\
\hline WCC social support & 53 & $20.45 \pm 5.46$ & 24 & $19.25 \pm 5.57$ & 29 & $21.45 \pm 5.25$ & 0.146 \\
\hline \multicolumn{8}{|c|}{ SSQ: Social Support Questionnaire } \\
\hline SSQ availability & 53 & $13.0(8.0-16.0)$ & 24 & $14.0(9.0-15.0)$ & 29 & $13.0(8.0-16.0)$ & 0.943 \\
\hline SSQ satisfaction & 53 & $30.0(26.0-34.0)$ & 24 & $29.5(24.5-34.0)$ & 29 & $30.0(28.0-36.0)$ & 0.181 \\
\hline \multicolumn{8}{|c|}{ MHLC-C: Multidimensional Health Locus of Control } \\
\hline Internal & 55 & $19.33 \pm 6.21$ & 25 & $19.52 \pm 6.20$ & 30 & $19.17 \pm 6.31$ & 0.835 \\
\hline External: chance & 55 & $20.65 \pm 6.48$ & 25 & $19.84 \pm 6.40$ & 30 & $21.33 \pm 6.58$ & 0.400 \\
\hline External: doctors & 55 & $15.00(12.0-17.0)$ & 25 & $15.00(12.0-17.0)$ & 30 & $15.50(12.0-17.0)$ & 0.820 \\
\hline External: others & 55 & $10.78 \pm 3.69$ & 25 & $11.48 \pm 3.86$ & 30 & $10.20 \pm 3.49$ & 0.202 \\
\hline
\end{tabular}

Data are presented as mean \pm SD or median (interquartile range), unless otherwise stated. PCS: Physical Composite Summary; MCS: Mental Composite Summary.

Risk assessment in PAH currently relies on parameters from clinical, haemodynamic, echographic, cardiopulmonary exercise testing and specific biomarker assessments. HRQoL has never been previously assessed in this regard. Surprisingly, HRQoL did not statistically decline over time. However, baseline values were associated with disease progression. This reinforces the results of a retrospective study by MCCABE et al. [17] suggesting that the predictive value of the CAMPHOR Questionnaire is also restricted to baseline values. These results suggest that HRQoL monitoring can provide additional useful and complementary information to the traditional PAH work-up, but does not need to be carried out at overly frequent intervals.

In addition, several psychological variables differed between the progression-free and disease-progression groups at baseline, indicating that the latter individuals have stronger anxiety (trait and state anxiety) and depression and resort more often to emotional coping strategies to deal with daily stressors. However, at the multivariable level, the only psychological variable associated with HRQoL was depression. The reader should note that the study cohort included one-quarter incident patients, and these patterns may be specific to patients in the process of disease discovery.

As specifically concerns coping with stressful life events (WCC) and with the disease (CHIP), baseline values for the total population highlighted strategies that were primarily problem-focused, indicating a 


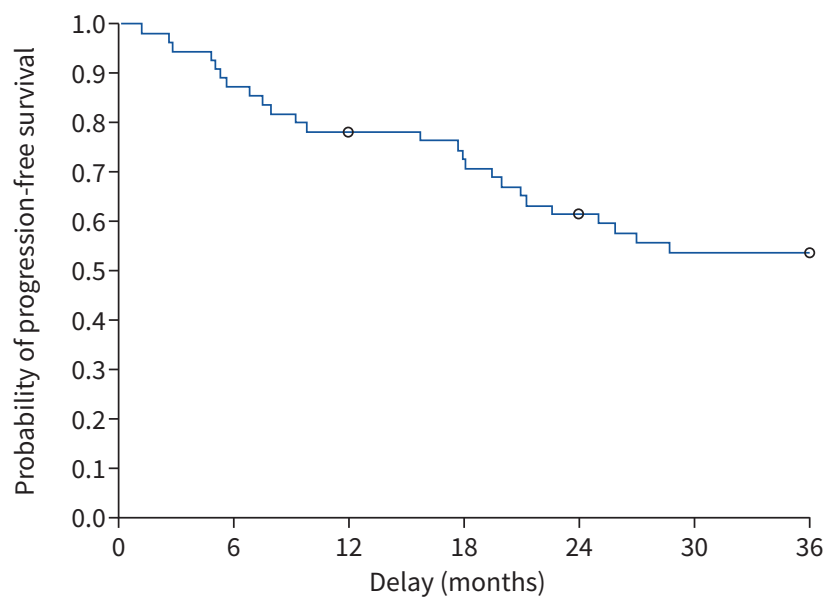

Number of patients at risk

$\begin{array}{lllllll}55 & 48 & 43 & 39 & 33 & 28 & 28\end{array}$

FIGURE 1 Progression-free survival. Aggravation occurred linearly.

TABLE 4 Univariate and multivariable Cox model results describing associations between baseline clinical variables and progression-free survival

Hazard ratio

$95 \% \mathrm{Cl}$

p-value

\section{Univariate analysis}

New York Heart Association stage $\quad 2.083 \quad 1.250-3.470 \quad 0.0048$

Pulmonary capillary pressure $(\mathrm{mmHg}) \quad 1.043$

Cardiac output (L· $\left.\mathrm{min}^{-1}\right) \quad 1.267$

Pulmonary vascular resistance (Wood's units) $\quad 1.008$

Right atrium pressure $(\mathrm{mmHg})$

6-min walk test

Distance $(\mathrm{m})$

Distance $(m)>440 m$ versus $\leqslant 440 m$

Borg test $\quad 1.006$

$\begin{array}{ll}1.250-3.470 & 0.0048^{\#} \\ 1.013-1.065 & 0.0028^{\#}\end{array}$

Cardiac frequency (bpm)

Baseline 1.004

End 1.018

$\begin{array}{lll}1.004 & 0.947-1.064 & 0.9011\end{array}$

Oxygen saturation (\%)

Baseline 0.896

End 0.937

$\Delta \geqslant 4 \%$

4.144

Physical functionin

Role-physical

Bodily pain

0.981

0.986

General health

0.991

Vitality

0.987

0.977

Social functioning

0.983

Role-emotional

0.988

Mental health

0.976

$0.923-1.180$

0.4969

$0.996-1.612$

$0.0535^{\#}$

$0.952-1.067$

0.7796

ultivariate analysis

SF-36 Questionnaire: physical functioning

0.978

Mean pulmonary arterial pressure $(\mathrm{mmHg})$

1.053

1.559

$0.985-1.053$

0.2852

Cardiac output $\left(\mathrm{L} \cdot \mathrm{min}^{-1}\right)$

$0.821-0.977$

$0.0132^{\#}$

$0.902-0.974 \quad 0.0010^{\#}$

$0.534-32.16$

0.1739

$\Delta \geqslant 4 \%$ : change in oxygen saturation over 4\%; SF-36: 36 -item Short-Form Health Survey. \#: variables with a univariate $p<0.15$ were retained for multivariable analysis. 
tendency to want to control the situation [16]. However, in the disease-progression group, such coping strategies (WCC) were more focused on emotional responses. Additionally, when examining the relationships between baseline psychological variables and the HRQoL PF subscale, a significant negative association with the CHIP Emotion score was demonstrated.

People living with PAH are particularly vulnerable when they are newly diagnosed or when they have to deal with the loss of a fellow patient or with a change in treatment. Emotion-focused coping may be the only realistic option when the source of stress is outside the person's control. Furthermore, emotion-focused coping is usually linked to poor HRQoL and associated with symptoms of depression and anxiety [18], as for our PAH disease-progression group.

Previous studies have remarked upon the presence of (presumably) state anxiety, which can be observed to accumulate or peak during: 1) the waiting-for-a-diagnosis period [19], 2) the moment when a PAH diagnosis is announced, or just prior to 3) key progression-determining exams such as right heart catheterisation [20] or 6MWT (in our clinical experience). An additional key moment is the initiation of prostacyclin treatment as well demonstrated by SHAFAzAND et al. [13], where state anxiety decreases during treatment. An amelioration of mood disorders following PAH diagnosis and treatment has been previously observed [21].

Our results place a new-found importance on trait anxiety, i.e. a nonmodifiable and functional personality trait. Patients with an anxious personality type are likely to have a poorer HRQoL, regardless of incident/ prevalent status or therapy type (bi- or tri-therapies) [16]. This observation in PAH is important because in-depth work on their life story will be more beneficial than exposure to fears as in behavioural and cognitive therapies designed to help manage state anxiety.

It is also quite interesting that depression was associated with the HRQoL PF score during multivariable analysis. The association of depression with decreased physical functioning has already been reported [22], and depression has been previously demonstrated as a predictor of reduced HRQoL [23]. Depression is common following the diagnosis of a serious illness. Depression disturbs thought and action and these problematic side-effects may interfere with a PAH patient's already compromised HRQoL. Associated directions of causality (Does physical degradation automatically lead to depression? Are non-depressed

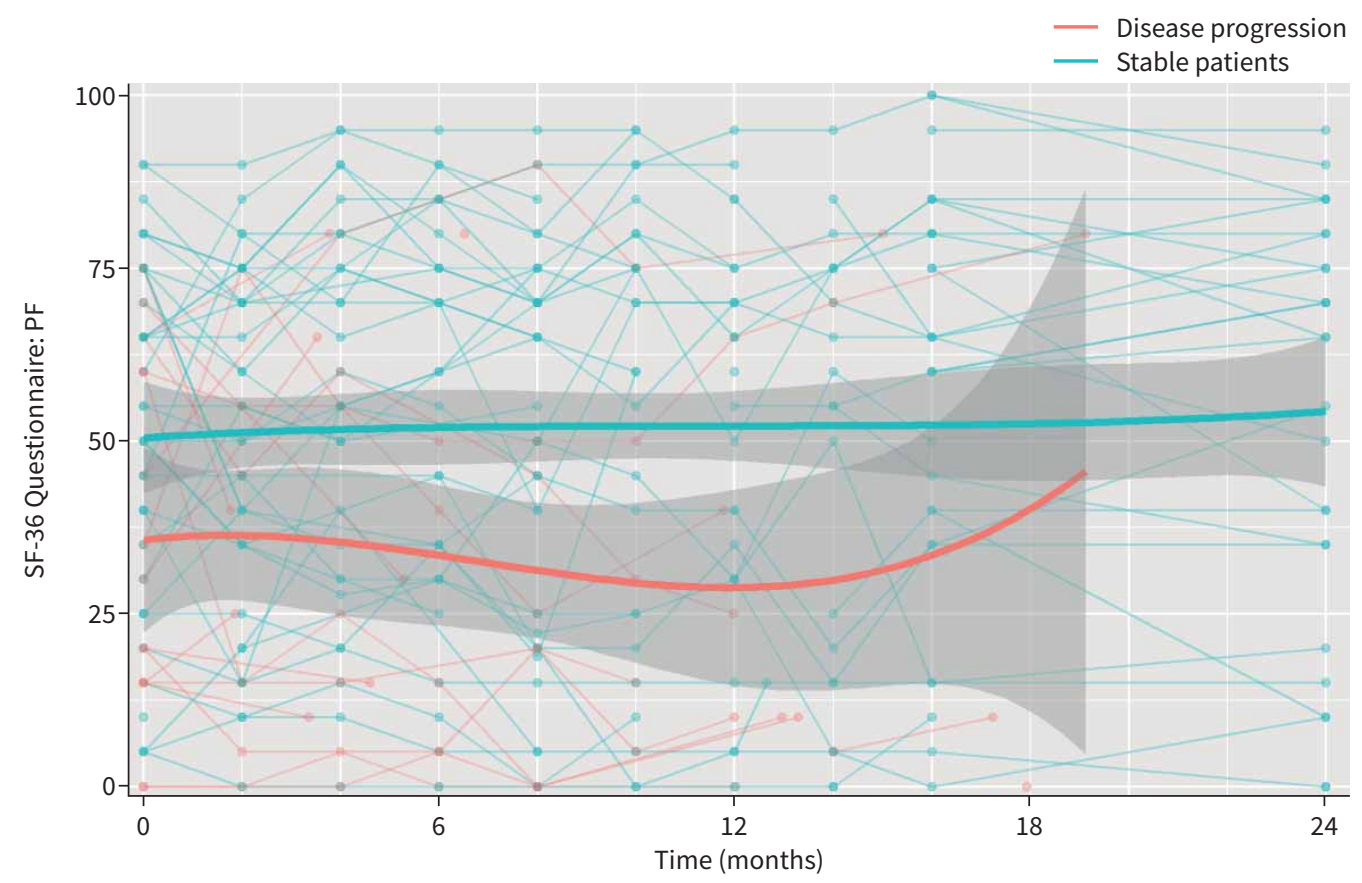

FIGURE 2 Physical functioning (PF) subscale of 36-item Short-Form Health Survey (SF-36) values over time. No association with time or the interaction term (stability $\times$ time) was found, indicating that the PF subscale was stable throughout the 3 years of complete follow-up. 

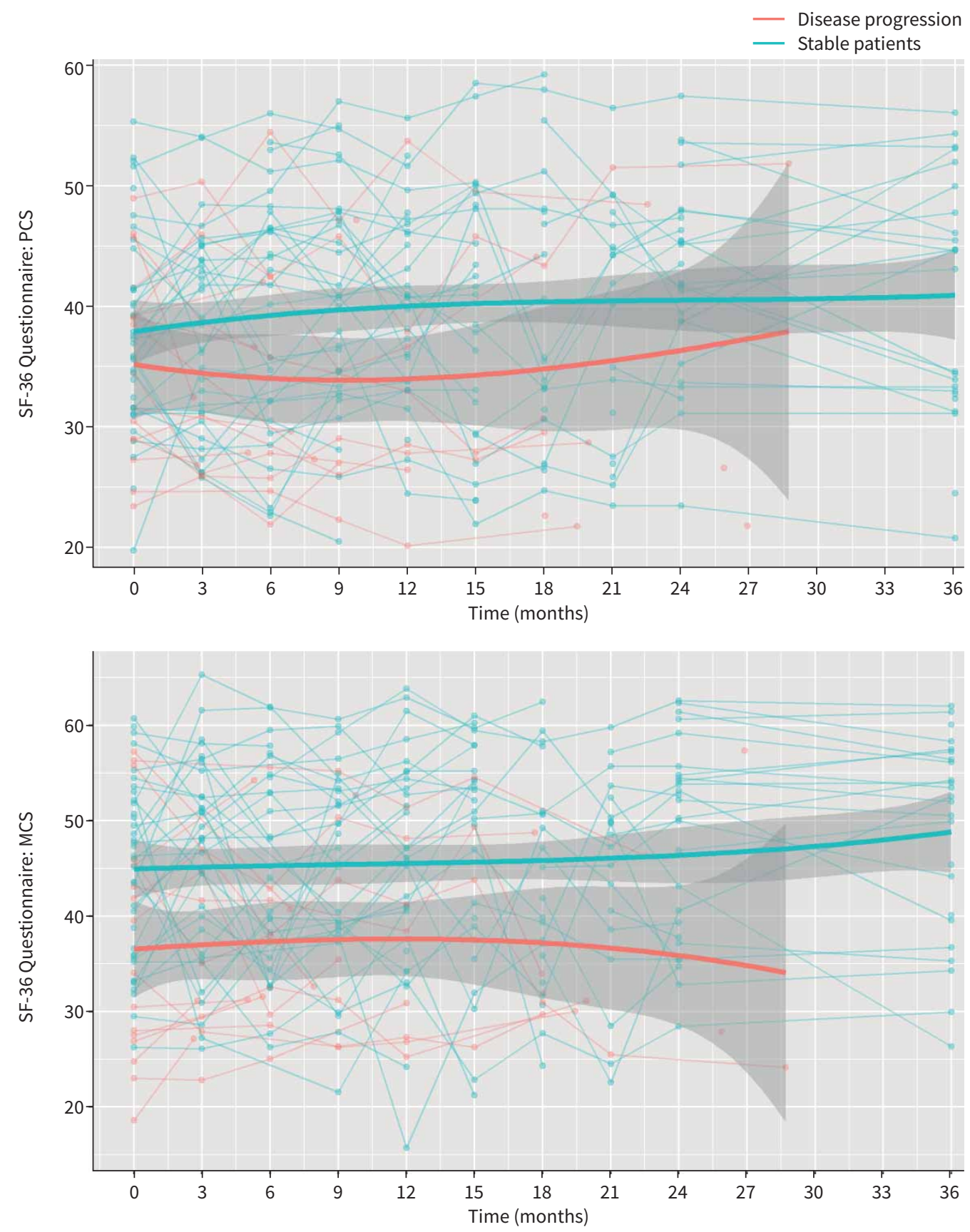

FIGURE 3 Mental Component Summary (MCS) and Physical Component Summary (PCS) values over time. No association with time or the interaction term (stability $\times$ time) was found, indicating that PCS and MCS were stable throughout the 3 years of complete follow-up. SF-36: 36-item Short-Form Health Survey.

patients adapting better to PAH? Does depression lead to a more pessimistic self-assessment of HRQoL $\mathrm{PF}$ ?) remain to be determined.

The PF subscale is designed to examine a person's perceived limitation in performing any physical activity [8]. It reflects a wide range of physical disability, which can cause significant changes in family life, financial situations and social interactions. All such perceived physical limitations can cause depression or be accentuated thereby; for example, certain patients may give up walking exercises to avoid the anxiety they cause. Fatigue and lack of energy may therefore be due to PAH and/or depression. Depression, like PAH, is difficult to recognise and understand, and in depression as in PAH, the suffering is internal, with few visible external signs. Identifying and treating depression is therefore essential. 


\begin{tabular}{|c|c|c|c|}
\hline & Coefficient & Standard error & $\mathrm{p}$-value \\
\hline \multicolumn{4}{|l|}{ Univariate analysis } \\
\hline \multicolumn{4}{|l|}{ HADS } \\
\hline HADS total & -1.81 & 0.41 & $<0.0001^{\#}$ \\
\hline HADS anxiety & -2.08 & 0.71 & $0.0007^{\#}$ \\
\hline HADS depression & -3.51 & 0.77 & $<0.0001^{\#}$ \\
\hline \multicolumn{4}{|l|}{ STAI-Y } \\
\hline State anxiety & -0.99 & 0.47 & $0.0393^{\#}$ \\
\hline Trait anxiety & -0.80 & 0.22 & $0.0007^{\#}$ \\
\hline \multicolumn{4}{|l|}{ CHIP } \\
\hline Distraction & 1.05 & 0.53 & $0.0558^{\#}$ \\
\hline Instrumental & 0.84 & 0.59 & 0.1539 \\
\hline Emotional preoccupation & -1.12 & 0.46 & $0.0187^{\#}$ \\
\hline Palliative & 0.20 & 0.77 & 0.7995 \\
\hline \multicolumn{4}{|l|}{ WCC } \\
\hline Problem-focused & 0.74 & 0.65 & 0.2580 \\
\hline Emotion-focused & -1.07 & 0.61 & $0.0859^{\#}$ \\
\hline Search for social support & 0.54 & 0.65 & 0.4160 \\
\hline \multicolumn{4}{|l|}{ SSQ6 } \\
\hline Availability & 0.28 & 0.38 & 0.4692 \\
\hline Satisfaction & -0.12 & 0.52 & 0.8204 \\
\hline \multicolumn{4}{|l|}{ MHLC-C } \\
\hline Internal locus of control & 0.74 & 0.57 & 0.2005 \\
\hline \multicolumn{4}{|l|}{ External locus of control } \\
\hline Chance & 0.55 & 0.56 & 0.3293 \\
\hline Doctors & 0.19 & 1.00 & 0.8467 \\
\hline Powerful others & -1.48 & 0.97 & $0.1342^{\#}$ \\
\hline \multicolumn{4}{|l|}{ Multivariate analysis } \\
\hline HADS depression & -3.26 & 0.79 & 0.0001 \\
\hline $\begin{array}{l}\text { HADS: Hospital Anxiety Depre } \\
\text { Health Injuries and Problems; } \\
\text { Multidimensional Health Locus } \\
\text { retained for multivariable analys }\end{array}$ & $\begin{array}{l}\text { STAI-Y: State } \\
\text { f coping Che } \\
\text { old indicates }\end{array}$ & $\begin{array}{l}\text { Inventory Form } \\
\text { ocial Support Q } \\
\text { variables with a }\end{array}$ & $\begin{array}{l}\text { ping with } \\
\text {; MHLC-C: } \\
0.15 \text { were }\end{array}$ \\
\hline
\end{tabular}

The limitations of this study include its observational, single-centre nature and sample size, although the latter is actually quite large compared to most PAH studies and reflects the relative rarity of the disease. In addition, disease-specific quality of life tools, such as the CAMPHOR [24], have not been validated in French. As a result, and due to the lack of a minimally clinical important difference for the CAMPHOR [7] and a demonstrated lack of predictive value for repeated CAMPHOR measures [17], we chose a generic measure (the SF-36). The latter, although known to be highly correlated with the CAMPHOR [25], may not be as sensitive to changes in PAH populations [26]. In this case, the patterns in this paper can be considered as conservative in nature. Many authors in the domain have chosen the SF-36 over disease-specific tools even when the latter exist in their languages because it is better known, rapid, easy and reliable [5, 7]. Additionally, the SF-36 has been demonstrated as responsive to change in PAH drug trials [27]. It is also surprising to find that 6MWT distance $>400 \mathrm{~m}$ was not retained at the multivariate level (table 4) as it has been demonstrated as quite predictive in previous studies [28]. However, this is probably due to the small sample sizes involved. Utmost care was also taken to convince patients to participate in follow-up activities, and our dataset reports no loss to follow-up, which is a great strength. A further strength is the power-supporting, repeated, 3-monthly measures of HRQoL, which, to our knowledge, have not been previously reported for $\mathrm{PAH}$ populations.

Finally, the patients included in this cohort were treated for anxiety and depression, including in-house psychological support every 3 months if needed and at times of acute disease decline, in accordance with current recommendations [4]. Guidelines for the use of psychological tests stress that the administration of psychological assessments via telephone, via postal mail, in the presence of a doctor, or in the absence of a psychologist, without knowledge of the patient's psychological status on a given day, are all sources of 
bias that commonly appear in the literature [29] and that do not apply to the present study. How this might have affected our results in comparison with previous studies should be taken into account.

In conclusion, the positive independent association between the HRQoL PF subscale and progression-free survival starts at baseline, indicating that HRQoL is important complementary information in the work-up of PAH patients. The frequency of psychological symptoms is relatively high, but only depression is independently associated with HRQoL. Lastly, it is interesting to note that HRQoL, which was stable over time in the present cohort, was associated with depression that is also known to be potentially chronic over time. Identifying and treating depression is a major issue in the management of PAH. The patient's point of view regarding his/her health status is essential in decision-making procedures, and future studies by our team will focus on the words patients use to describe their disease, moods, behaviours and HRQoL. Given its independent association with decline, HRQoL should be further studied to elucidate its prognostic potential.

This study is registered at www.ClinicalTrials.gov with identifier number NCT01380054.

Author contributions: L. Halimi, I. Vachier, N. Molinari and A. Bourdin designed and wrote the study protocol. L. Halimi, C. Boissin, A-S. Gamez and A. Bourdin included and/or monitored patients and acquired data. N. Molinari, G. Marin and C.M. Suehs performed data wrangling and statistical analyses. L. Halimi wrote the first draft of the manuscript. All authors participated in data interpretation, manuscript revision and approved the final version of the manuscript.

Conflict of interest: L. Halimi has nothing to disclose. C.M. Suehs has nothing to disclose. G. Marin has nothing to disclose. C. Boissin has nothing to disclose. A-S. Gamez has nothing to disclose. I. Vachier has nothing to disclose. N. Molinari has nothing to disclose. A. Bourdin reports grants, personal fees, nonfinancial support and other from AstraZeneca, Boehringer Ingelheim, GlaxoSmithKline and Novartis; personal fees and nonfinancial support from Teva; personal fees, nonfinancial support and other from Regeneron and Chiesi Pharmaceuticals; grants, personal fees, nonfinancial support and other from Actelion; personal fees from Gilead; nonfinancial support and other from Roche; and other from Nuvaira, all outside the submitted work.

Support statement: The HyPsy protocol (https://osf.io/8qduc/) was partially funded by an unrestricted grant from GlaxoSmithKline. GlaxoSmithKline took no part in study design, data acquisition, analysis or interpretation of results. Funding information for this article has been deposited with the Crossref Funder Registry.

References

1 Thenappan T, Ormiston ML, Ryan JJ, et al. Pulmonary arterial hypertension: pathogenesis and clinical management. BMJ 2018; 360: j5492.

2 Humbert M, Sitbon O, Chaouat $\mathrm{A}$, et al. Pulmonary arterial hypertension in France: results from a national registry. Am J Respir Crit Care Med 2006; 173: 1023-1030.

3 Humbert M, Lau EMT, Montani D, et al. Advances in therapeutic interventions for patients with pulmonary arterial hypertension. Circulation 2014; 130: 2189-2208.

4 Galiè N, Humbert M, Vachiery J-L, et al. 2015 ESC/ERS Guidelines for the diagnosis and treatment of pulmonary hypertension: The Joint Task Force for the Diagnosis and Treatment of Pulmonary Hypertension of the European Society of Cardiology (ESC) and the European Respiratory Society (ERS). Eur Respir J 2015; 46: 903-975.

5 Fernandes CJCS, Martins BCS, Jardim CVP, et al. Quality of life as a prognostic marker in pulmonary arterial hypertension. Health Qual Life Outcomes 2014; 12: 130.

6 The World Health Organization quality of life assessment (WHOQOL): position paper from the World Health Organization. Soc Sci Med 1995; 41: 1403-1409.

7 Mathai SC, Suber T, Khair RM, et al. Health-related quality of life and survival in pulmonary arteria hypertension. Ann Am Thorac Soc 2016; 13: 31-39.

8 Ware JE, Sherbourne CD. The MOS 36-item short-form health survey (SF-36). I. Conceptual framework and item selection. Med Care 1992; 30: 473-483.

9 Gilbert C, Brown MCJ, Cappelleri JC, et al. Estimating a minimally important difference in pulmonary arterial hypertension following treatment with sildenafil. Chest 2009; 135: 137-142.

10 Simonneau G, Barst RJ, Galie N, et al. Continuous subcutaneous infusion of treprostinil, a prostacyclin analogue, in patients with pulmonary arterial hypertension: a double-blind, randomized, placebo-controlled trial. Am J Respir Crit Care Med 2002; 165: 800-804.

11 Rival G, Lacasse Y, Martin S, et al. Effect of pulmonary arterial hypertension-specific therapies on health-related quality of life: a systematic review. Chest 2014; 146: 686-708. 
12 Rapkin BD, Schwartz CE. Toward a theoretical model of quality-of-life appraisal: implications of findings from studies of response shift. Health Qual Life Outcomes 2004; 2: 14.

13 Shafazand S, Goldstein MK, Doyle RL, et al. Health-related quality of life in patients with pulmonary arterial hypertension. Chest 2004; 126: 1452-1459.

14 McCollister DH, Beutz M, McLaughlin V, et al. Depressive symptoms in pulmonary arterial hypertension: prevalence and association with functional status. Psychosomatics 2010; 51: 339-339.

15 Hall H, Côté J, McBean A, et al. The experiences of patients with pulmonary arterial hypertension receiving continuous intravenous infusion of epoprostenol (Flolan) and their support persons. Heart Lung J Crit Care 2012; 41: 35-43.

16 Halimi L, Marin G, Molinari N, et al. Impact of psychological factors on the health-related quality of life of patients treated for pulmonary arterial hypertension. J Psychosom Res 2018; 105: 45-51.

17 McCabe C, Bennett M, Doughty N, et al. Patient-reported outcomes assessed by the CAMPHOR questionnaire predict clinical deterioration in idiopathic pulmonary arterial hypertension and chronic thromboembolic pulmonary hypertension. Chest 2013; 144: 522-530.

18 Graven LJ, Grant JS. Coping and health-related quality of life in individuals with heart failure: an integrative review. Heart Lung J Crit Care 2013; 42: 183-194.

19 Tsangaris I. Improving patient care in pulmonary arterial hypertension: addressing psychosocial issues. J Clin Hypertens Greenwich Conn 2014; 16: 159-161.

20 Harkness K, Morrow L, Smith K, et al. The effect of early education on patient anxiety while waiting for elective cardiac catheterization. Eur J Cardiovasc Nurs 2003; 2: 113-121.

21 Somaini G, Hasler ED, Saxer S, et al. Prevalence of anxiety and depression in pulmonary hypertension and changes during therapy. Respir Int Rev Thorac Dis 2016; 91: 359-366.

22 Looper KJ, Pierre A, Dunkley DM, et al. Depressive symptoms in relation to physical functioning in pulmonary hypertension. J Psychosom Res 2009; 66: 221-225.

23 Yorke J, Deaton C, Campbell M, et al. Symptom severity and its effect on health-related quality of life over time in patients with pulmonary hypertension: a multisite longitudinal cohort study. BMJ Open Respir Res 2018; 5: e000263.

24 McKenna SP, Doughty N, Meads DM, et al. The Cambridge Pulmonary Hypertension Outcome Review (CAMPHOR): a measure of health-related quality of life and quality of life for patients with pulmonary hypertension. Qual Life Res 2006; 15: 103-115.

25 Gastelurrutia P, Lupón J, Altimir S, et al. Effect of fragility on quality of life in patients with heart failure. Am J Cardiol 2013; 112: 1785-1789.

26 Twiss J, McKenna S, Ganderton L, et al. Psychometric performance of the CAMPHOR and SF-36 in pulmonary hypertension. BMC Pulm Med 2013; 13: 45.

27 Pepke-Zaba J, Gilbert C, Collings L, et al. Sildenafil improves health-related quality of life in patients with pulmonary arterial hypertension. Chest 2008; 133: 183-189.

28 Souza R, Channick RN, Delcroix M, et al. Association between six-minute walk distance and long-term outcomes in patients with pulmonary arterial hypertension: data from the randomized SERAPHIN trial. PLOS ONE 2018; 13: e0193226.

29 International Test Commission. International Guidelines for Test Use. Int J Test 2001; 1: 93-114.

30 Zigmond AS, Snaith RP. The hospital anxiety and depression scale. Acta Psychiatr Scand 1983; 67: 361-370.

31 Lépine JP, Godchau M, Brun P, et al. Evaluation de l'anxiété et de la dépression chez des patients hospitalisés dans un service de médecine interne. Ann Med Psychol Paris 1985; 143: 175-189.

32 Spielberger CD, Jacobs G, Russell S, et al. Assessment of anger: The State-Trait Anger Scale. In: JN Butcher and CD Speilberger, eds. Advances in Personality Assessment, Vol. 2. Hillsdale, Lawrence Erlbaum Associates, Inc., 1983; pp. 159-187.

33 Spielberger CD, Bruchon-Schweitzer M, Paulhan I. Inventaire d'anxiété État-Trait: Forme Y. Paris, ECPA, les Éditions du centre de psychologie appliquée, 1993.

34 Montel S, Bungener C. [Validation of CHIP (a coping questionnaire) in French patients with neurological disorders]. Rev Neurol (Paris) 2010; 166: 54-60.

35 Endler NS, Parker JD, Summerfeldt LJ. Coping with health problems: developing a reliable and valid multidimensional measure. Psychol Assess 1998; 10: 195-205.

36 Lazarus RS, Folkman S. Coping and adaptation. In: WD Gentry, ed. The Handbook of Behavioral Medicine. New York, Guilford, 1984; pp. 282-325.

37 Bruchon-Schweitzer M, Cousson F, Quintard B, et al. French adaptation of the Ways of Coping Checklist. Percept Mot Skills 1996; 83: 104-106.

38 Sarason IG, Levine HM, Basham RB, et al. Assessing social support: the Social Support Questionnaire. J Pers Soc Psychol 1983; 44: 127.

39 Bruchon-Schweitzer M. Psychologie de la santé: modèles, concepts et méthodes. Paris, Dunod, 2003.

40 Wallston KA, Stein MJ, Smith CA. Form C of the MHLC scales: a condition-specific measure of locus of control. J Pers Assess 1994; 63: 534-553. 